Article

\title{
Modular Chitosan-Based Adsorbents for Tunable Uptake of Sulfate from Water
}

\author{
Bernd G. K. Steiger 1 and Lee D. Wilson *(D) \\ Department of Chemistry, University of Saskatchewan, 110 Science Place, Saskatoon, SK S7N 5C9, Canada; \\ bes241@mail.usask.ca \\ * Correspondence: lee.wilson@usask.ca; Tel.: +1-306-966-2961; Fax: +1-306-966-4730
}

Received: 26 August 2020; Accepted: 21 September 2020; Published: 27 September 2020

\begin{abstract}
The context of this study responds to the need for sorbent technology development to address the controlled removal of inorganic sulfate $\left(\mathrm{SO}_{4}{ }^{2-}\right)$ from saline water and the promising potential of chitosan as a carrier system for organosulfates in pharmaceutical and nutraceutical applications. This study aims to address the controlled removal of sulfate using chitosan as a sustainable biopolymer platform, where a modular synthetic approach was used for chitosan bead preparation that displays tunable sulfate uptake. The beads were prepared via phase-inversion synthesis, followed by cross-linking with glutaraldehyde, and impregnation of $\mathrm{Ca}^{2+}$ ions. The sulfate adsorption properties of the beads were studied at $\mathrm{pH} 5$ and variable sulfate levels (50-1000 ppm), where beads with low cross-linking showed moderate sulfate uptake $(35 \mathrm{mg} / \mathrm{g})$, while cross-linked beads imbibed with $\mathrm{Ca}^{2+}$ had greater sulfate adsorption $(140 \mathrm{mg} / \mathrm{g})$. Bead stability, adsorption properties, and the point-of-zero charge (PZC) from 6.5 to 6.8 were found to depend on the cross-linking ratio and the presence of $\mathrm{Ca}^{2+}$. The beads were regenerated over multiple adsorption-desorption cycles to demonstrate the favorable uptake properties and bead stability. This study contributes to the development of chitosan-based adsorbent technology via a modular materials design strategy for the controlled removal of sulfate. The results of this study are relevant to diverse pharmaceutical and nutraceutical applications that range from the controlled removal of dextran sulfate from water to the controlled release of chondroitin sulfate.
\end{abstract}

Keywords: adsorption; chitosan beads; sulfate; surface modification; calcium imbibing; cross-linking

\section{Introduction}

Saline ground and surface water deposits pose a significant concern to global water and food security, especially in developing countries. Sulfate is an important oxyanion component in saline ground water and aquifers due to its high solubility and mobility. However, the role of sulfate is often underestimated due to its relatively low toxicity [1]. At elevated sulfate levels (ca. 250-500 mg/L and greater), adverse health effects include diarrhea, especially for children since they are more susceptible than adults [2,3]. Climate change and increased irrigation for food production may exacerbate the detrimental effects of water salinity [4,5], where projections forecast negative impacts on global water security [6]. In countries such as the USA and Canada, sulfate contamination is attributed to the erosion of naturally abundant magnesium sulfate and gypsum deposits. Further, sulfur emissions by industry can reach critical levels in wastewater that contribute to ecosystem disruption. Sulfate from geochemical sources have been related to elevated sulfate levels that can range from $6500 \mathrm{mg} / \mathrm{L}$ to 20,000 mg/L in dug-outs of Saskatchewan, Canada's agricultural bread basket [7,8].

Currently, sulfate remediation does not generally employ adsorption-based methods, even though adsorbent technology can provide benefits in terms of cost, environmental and maintenance over other types of physical and chemical removal methods [9-15]. Adsorption-based removal of sulfate 
offers a relatively low-cost approach with variable efficiency and selectivity [16]. The merits of the adsorption process are generally limited by the availability of an adsorbent material with suitable properties. In contrast to petrochemical-based ion-exchange resins for efficient adsorptive removal, there is renewed interest in the development of sustainable biopolymer adsorbents using chitosan-based materials. Chitin is a natural biopolymer with a poly( $\beta-(1-4)-N$-acetyl-D-glucosamine) structure that is the second most abundant biopolymer after cellulose $[16,17]$. Chitosan is typically obtained from chitin via deacetylation pathways, where the structural similarity of cellulose and chitosan relate to differences in the chemical functionality at the $\mathrm{C} 2$-carbon. The presence of $-\mathrm{NH}_{2}$ instead of $-\mathrm{OH}$ groups result in variable chemical reactivity along with a unique solubility profile of chitosan in organic and mineral acids (except for sulfuric and phosphoric acid), along with the metal chelation properties of the glucosamine monomer units of chitosan [18]. The solubility of chitosan results from the protonation of its amine groups which can coordinate with anionic species or undergo ion-exchange with multivalent metal cations, further revealing its unique adsorption properties $[19,20]$. Pristine chitosan has some limitations in terms of its low accessible surface area, low mechanical stability, and only partial accessibility of its functional groups, due to its semi-crystalline structure $[18,21]$. To address these limitations, synthetic modification of chitosan via physical or chemical cross-linking have been reported [22-24]. Examples of chemical cross-linkers used to modify the physicochemical properties of chitosan include epichlorohydrin and glutaraldehyde $[25,26]$. The controlled removal of oxyanions, such as arsenates and vanadates, has been reported [27-29], along with organic dyes and organophosphates from wastewater [26,30-33]. Modified chitosan adsorbents have been employed for the removal of oxyanions with variable solubility profiles and ionic charge that include sulfate, phosphate, and nitrate. [34,35].

In contrast with reported work on phosphate and nitrate adsorption, fewer studies are available on the adsorption of sulfate (cf. Supplementary Figure S1), in agreement with recent reviews that outline the adsorptive removal of other types of oxyanions [36-39]. The ubiquitous occurrence of sulfate in aquatic environments relate to its role as a competitive anion that influences the uptake efficiency of other target oxyanion species [40]. Sulfate as a competitor anion is supported by a recent study of mixed anions $\left(\mathrm{Cl}^{-}, \mathrm{HCO}_{3}{ }^{-}\right.$, and $\left.\mathrm{SO}_{4}{ }^{2-}\right)$ [41]. Similar to chitosan, sparse reports are available for chitin materials in the form of shrimp shells and grafted composite materials have been reported for sulfate removal from aqueous sources [15]. The chitosan bead systems offer various benefits over its pristine form, e.g., reduced back pressure in column application and increased flow rate [42]. Therefore, the present work relates to the to the modular materials design of chitosan beads with tunable sulfate adsorption properties via a phase-inversion synthesis of chitosan beads with sequential glutaraldehyde cross-linking and bead surface modification by $\mathrm{Ca}^{2+}$ doping (cf. Figure 1). Through this modular materials design, it is posited that chitosan beads prepared by this route will display incremental sulfate adsorption properties, in a parallel fashion as reported for other metal-oxyanion $\left(\mathrm{CrO}_{4}{ }^{2-}\right)$ systems with other co-adsorbed metal species [35,43-46]. Furthermore, this study builds upon work related to the adsorptive removal of oxyanions (phosphate and nitrate) outlined in a recent review [36]. This study exemplifies a sustainable and scalable synthesis that embodies elements of green chemistry for the design of chitosan-based adsorbents for sulfate as model anion for sulfate or sulfonated species (e.g., methyl orange, reactive black 5, dextran sulfate) [47]. It is posited that an improved understanding of the adsorption properties of sulfate, as a model anion, may relate to improved insight on the adsorption/desorption characteristics of relevant carrier systems for the uptake of lipid adducts or release of chondroitin sulfate. Other potential applications include dietary control and osteoarthritis strategies, respectively [48,49].

In light of the limited reports on sulfate adsorption, the present work was motivated to develop improved chitosan-based adsorbents for controlled sulfate removal due to the relevance of sulfate species to global water security and pharmaceutical/nutraceutical applications for this thematic journal issue. 


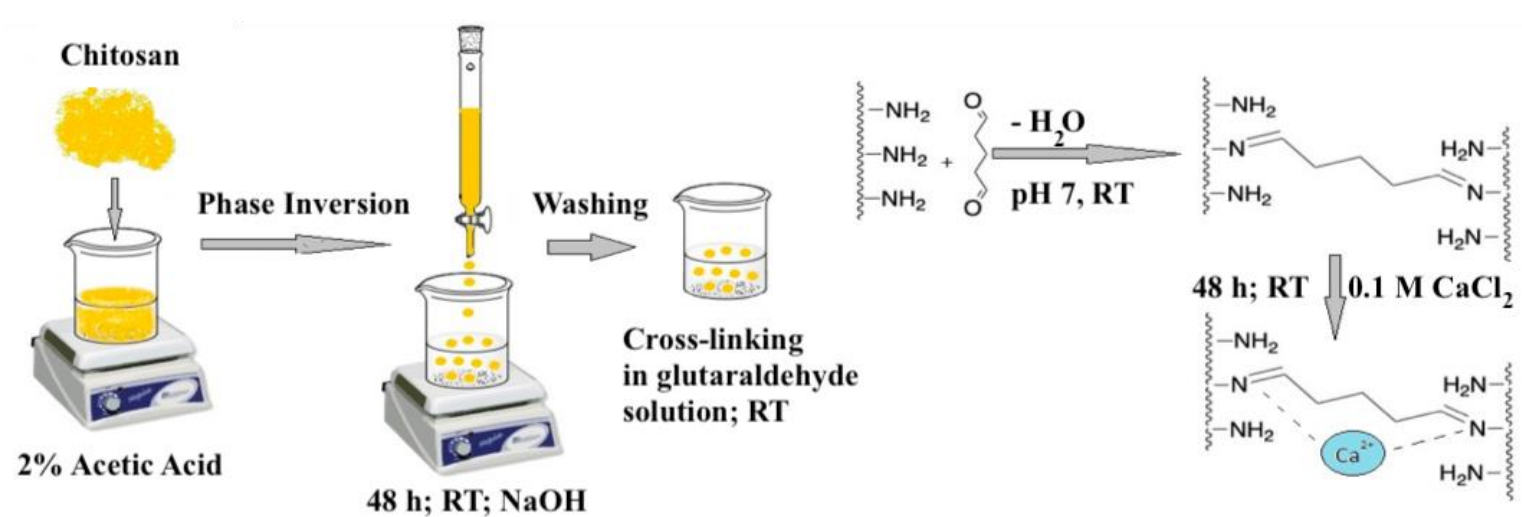

Figure 1. Schematic view of the synthesis of chitosan-derived beads under phase inversion synthesis with subsequent cross-linking via Schiff-base formation with glutaraldehyde and calcium-ion imbibing.

\section{Results}

As outlined above, the limited research on suitable biopolymer adsorbents for inorganic sulfate led us to the modular adsorbent design strategy in Figure 1. Following the modular synthesis of the chitosan bead systems herein, several complementary techniques are used to characterize the structure and physicochemical properties of the bead systems relevant to adsorption of sulfate, as outlined below.

\section{1. ${ }^{13}$ C NMR Spectral Result}

${ }^{13} \mathrm{C}$-solid state NMR spectroscopy is a sensitive method for detecting ${ }^{13} \mathrm{C}$ nuclei in unique chemical environments. The resulting ${ }^{13} \mathrm{C}$ NMR spectra (cf. Figure 2) reflect differences in chemical modification of chitosan due to differences in abundance and chemical shift information. Thus, ${ }^{13} \mathrm{CNMR}$ spectral results enable evaluation of the role of different levels of chemical modification that result upon cross-linking with glutaraldehyde at variable levels and calcium imbibing, as compared with pristine chitosan.

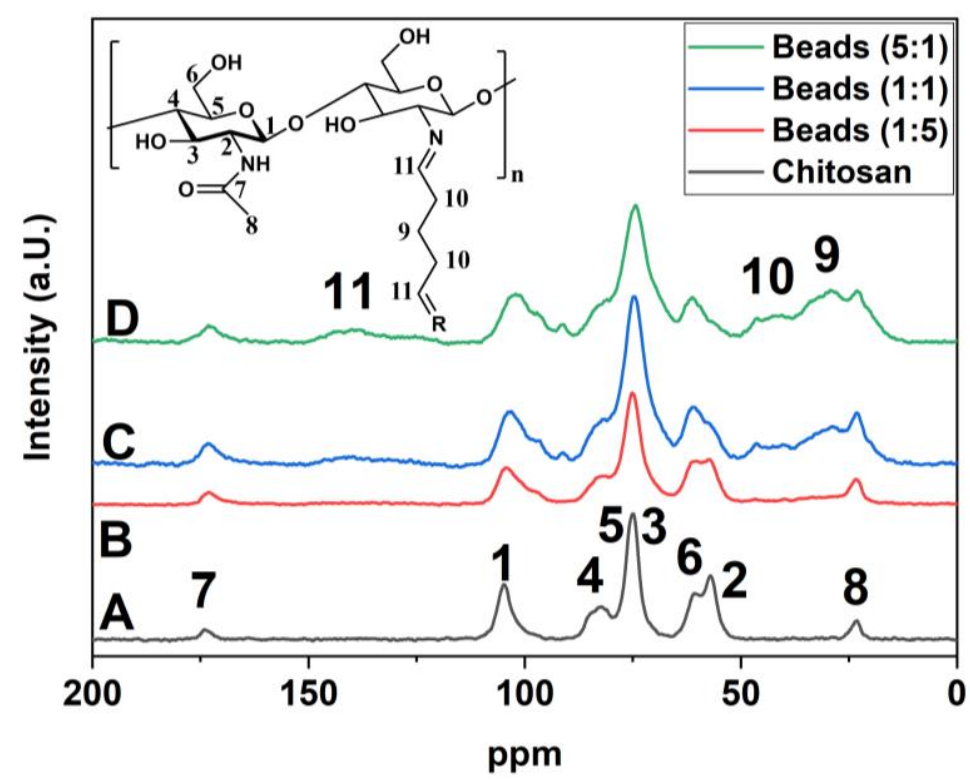

Figure 2. Solids ${ }^{13} \mathrm{C}$ CP-MAS NMR spectra at $125 \mathrm{MHz}$ : chitosan (no calcium) (A), calcium imbibed beads cross-linked at variable cross-linking (CL) ratios of glutaraldehyde to chitosan monomer units of 1:5 (B), 1:1 (C) and 5:1 (D). 
The ${ }^{13} \mathrm{C}$ solids NMR spectra reveal that imine cross-linkages are more evident at higher ratios (1:1 and above ca. 140 ppm for newly formed N=C-groups; see peak 11 in Figure 2C,D), along with signatures ca. 20 and 45 ppm (peak number 9 and 10) for the presence of aliphatic carbons of glutaraldehyde. This trend corresponds to the level of glutaraldehyde cross-linking, where a stoichiometric excess of glutaraldehyde is required for effective cross-linking at these conditions. Also, the spectral intensity of the $\mathrm{N}=\mathrm{C}$-groups in the bead are influenced by the presence of $\mathrm{Ca}^{2+}$ due to the role of chelation on the cross-polarization dynamics of the system [50]. Aside from the NMR spectral confirmation of the products reported in Figure 2, there is a need to characterize the thermal stability of the biopolymer network since thermal analysis was reported to be sensitive to be sensitive toward the structure and bonding variability of the chitosan composites, as described elsewhere [51]. The results in Figure 3 outline the thermal analysis profiles for the bead systems.

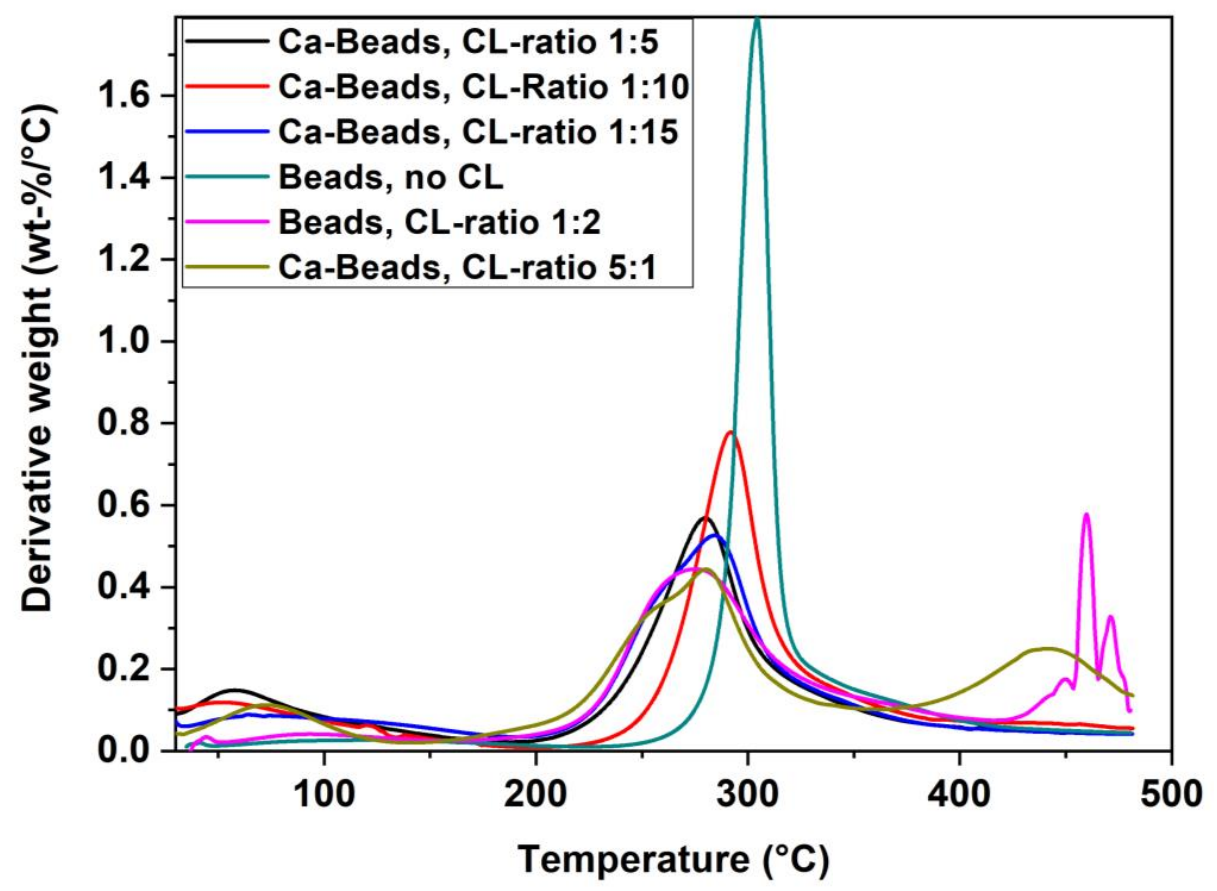

Figure 3. TGA profiles of the calcium doped beads with variable cross-linking (CL) ratios relative to the non-imbibed chitosan beads without cross-linking (no CL). The derivative weight scaling is truncated for the latter bead system.

\subsection{Thermogravimetric Analysis (TGA) Results}

The TGA results obtained for the chitosan materials provide a complementary approach for studying the physical properties of structurally similar systems [51-53]. Herein, we compared the TGA profiles of the chitosan beads after incremental chemical modification (cross-linking and imbibing) to reveal the role of the modular synthesis (cf. Figure 1) on the structure and thermal stability of such systems.

In Figure 3, there are several observable thermal events that relate to the chemical nature of the chitosan bead system. The decomposition event for non-cross-linked chitosan beads can be described as a relatively sharp thermal event near $300^{\circ} \mathrm{C}$ with a relatively narrow temperature interval that begins near $275{ }^{\circ} \mathrm{C}$ and spans up to ca. $325^{\circ} \mathrm{C}$. In comparison, the cross-linked chitosan beads have a lower average onset decomposition temperature that occurs near $250^{\circ} \mathrm{C}$ that cover a broader range up to ca. $330^{\circ} \mathrm{C}$, including other thermal events near $450{ }^{\circ} \mathrm{C}$. The lower temperature onset of cross-linked chitosan and the broadened temperature range reveal its overall lower thermal stability, as compared with beads without cross-linking. In a previous report, unmodified chitosan was found to have more crystalline domains due to efficient hydrogen bonding, as compared to cross-linked chitosan [23]. Cross-linking results in defects of the chitosan network similar to that of $\mathrm{Ca}^{2+}$ species imbibed within 
the bead matrix (relative to pristine chitosan) by creating defects within the hydrogen bond network of the biopolymer. A comparison of the imbibed and non-imbibed systems in Figure 3 reveals trends in the thermal profiles that further support the role of surface modification (cross-linking) and incorporation of calcium species from the modular bead synthesis (cf. Figure 1). The TGA results reveal variable thermal stability of the bead systems, while the NMR results show distinctive structural effects of the chitosan framework upon cross-linking and imbibing of $\mathrm{Ca}^{2+}$. The cross-linking of beads with glutaraldehyde affect the internal and surface structure of such biopolymer systems due to "pillaring effects" of the chitosan bead [54]. The role of covalent cross-linking of chitosan and surface modification with $\mathrm{Ca}^{2+}$ correlate with trends in the thermal stability of the bead systems, as noted in the TGA profiles. The incorporation of cross-linker resulted in secondary thermal events and the role of $\mathrm{Ca}^{2+}$ imbibing is observed in Figure 3, as noted by band broadening, and temperature shifts in the TGA profile. The latter trend shows parallel agreement with attenuated motional dynamics of modified chitosan according to the ${ }^{13} \mathrm{C}$ NMR spectral broadening observed in Figure 2. Likewise, the TGA band broadening noted for the modified chitosan depend on the cross-linker content since the formation of imine linkages alter the H-bond network, as compared with pristine chitosan.

\subsection{Solvent Swelling in Water \& Dye-Based Surface Area Estimates}

A recent study of the solvent swelling properties was shown to provide complementary insight on the hydration and adsorption properties of chitosan biopolymers [55]. A simple yet informative method to measure solvent swelling can be estimated through the gravimetric determination of water uptake since chitosan-based adsorbents are known to undergo swelling in aqueous media [23]. In Figure 4, the results for the equilibrium solvent swelling in water are shown for chitosan beads with incremental structural modification (cross-linking and $\mathrm{Ca}^{2+}$ imbibing). While the non-modified beads show the highest level of water swelling (ca. 150\%), the cross-linked beads show reduced swelling due to the role of incremental cross-linking since it is known to limit the volumetric expansion of such cross-linked materials. Calcium imbibed beads with a cross-linking ratio (CL-ratio) show variable swelling as follows: $97 \%$ (1:10), 85\% (1:5), 58\% (1:1), and 53\% (5:1).

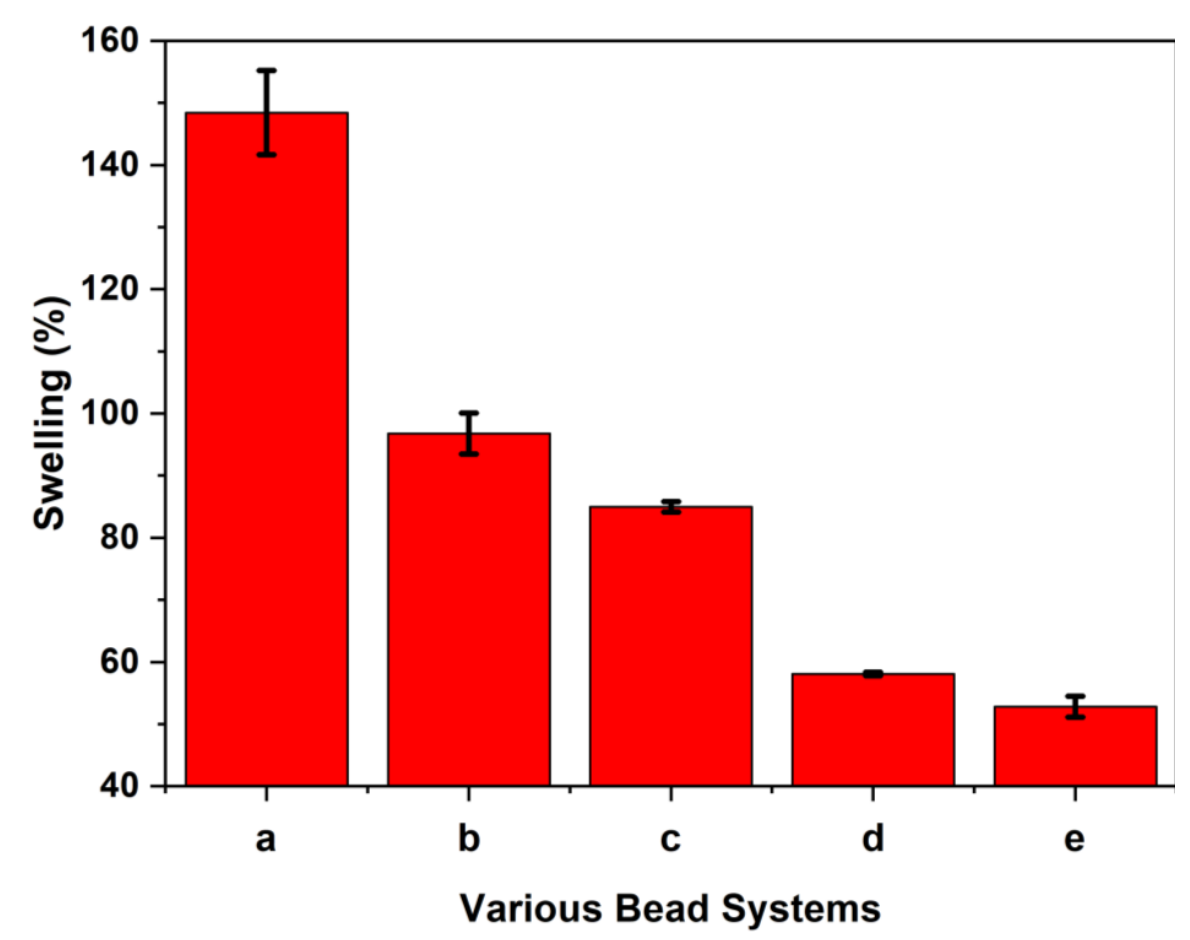

Figure 4. Swelling (\%) for chitosan bead systems: non-modified beads (a), calcium imbibed beads with a CL- ratio of 1:10 (b), non-imbibed beads with a CL-ratio of 1:5 (c), calcium imbibed beads with a CL-ratio of 1:1 (d) and 5:1 (e). 
In general, chitosan beads with higher cross-linking ratios often possess greater rigidity with less flexibility and greater steric effects, as evidenced by the reduced accessibility of the polymer chains [54]. In contrast to unmodified chitosan beads without cross-linking, the bead systems with incremental glutaraldehyde cross-linking show reduced water uptake and swelling. This trend in variable hydration and steric effects is supported by another study that reports on the variable accessibility of $\mathrm{N}$-containing functional groups of chitosan upon cross-linking [56]. The structural characterization of the different bead systems affirmed the effects of modification from the modular synthesis of chitosan in Figure 1. However, the role of chitosan modification and its relationship to the structure-adsorption properties of the bead systems with sulfate requires further study. Previous work indicates that cross-linking with glutaraldehyde converts the accessible amine groups to imine linkages and alteration of the bead physical properties $[24,25,57,58]$, in contrast to pristine chitosan beads without synthetic modification.

Gas adsorption is a conventional characterization method for estimating the surface area (SA) of adsorbent materials. In the case of biopolymer materials that undergo swelling in aqueous media, dye-based adsorption offers an alternative approach for estimating the adsorbent SA. The measurements were conducted at the isosbestic point of PNP to avoid errors due to changes in solution $\mathrm{pH}$ [59]. Herein, a dye-based method was employed, where $p$-nitrophenol (PNP) served as the dye probe for estimating the bead SA (cf. Table 1).

Table 1. Dye-based Surface Area (SA) using the anion form of PNP at $\mathrm{pH} 8.4 \pm 0.2$.

\begin{tabular}{cc}
\hline Bead System & $\mathbf{S A}\left(\mathbf{m}^{\mathbf{2}} \mathbf{g}^{-\mathbf{1}}\right)$ \\
\hline $5: 1 \mathrm{w} / \mathrm{Ca}^{2+}$ & $182 \pm 19$ \\
$1: 1 \mathrm{w} / \mathrm{Ca}^{2+}$ & $153 \pm 4$ \\
$1: 10 \mathrm{w} / \mathrm{Ca}^{2+}$ & $75 \pm 32$ \\
unmodified & $110 \pm 72$ \\
\hline
\end{tabular}

The molar surface area of PNP relates to its orthogonal orientation $\left(25 \times 10^{-20} \mathrm{~m}^{2}\right)$ where $Y=1$ (see Equation (1)), and the absorbance was measured at the isosbestic point of PNP $(\lambda=347 \mathrm{~nm})$.

$$
\mathrm{SA}\left(\frac{\mathrm{m}^{2}}{\mathrm{~g}}\right)=\frac{\mathrm{Q}_{\mathrm{m}} * \mathrm{~N} * \sigma_{\mathrm{PNP}}}{Y}
$$

$\mathrm{Q}_{\mathrm{m}}$ can be obtained from an analysis of the adsorption results using the Sips isotherm model (cf. Equation (2), where $Q_{m}$ represents the maximum monolayer adsorption capacity at equilibrium. The other terms in Equation (1) are also defined: $\mathrm{N}$ is Avogadro's number, $\sigma$ is the cross-sectional area of the adsorbate, and $Y$ is the coverage factor $(Y=1$ for PNP).

The effects of non-uniform drying can result in beads with non-uniform shape and size for systems without cross-linking. The size estimates of the various beads along with the mean, median and standard deviation are listed in Table S3 and Supplementary Figure S8. By contrast, cross-linked beads show more uniform spherical shape and size distributions that seem to stabilize the bead structure upon drying. Thus, the cross-linked bead systems show a general increase in SA over unmodified bead systems due to "pillaring effects" [54] related to cross-linking. While greater cross-linking results in reduced solvent swelling (cf. Figure 4), greater surface accessibility of the dye binding sites is supported by the greater SA estimates for beads with greater cross-linking in Table 1. This trend is contrasted to the unmodified (no cross-linking) bead systems. Notwithstanding the role of steric effects at elevated levels of cross-linking, incremental levels of glutaraldehyde contribute to a greater adsorption of PNP, in agreement with an independent study reported by Mohamed et al. [54] for the adsorption of naphthenate anion congeners by cross-linked chitosan polymers.

\subsection{X-ray Photoelectron Spectroscopy (XPS) Results}

XPS results for unmodified and cross-linked beads, with and without calcium imbibing are shown in the Supplementary Figures S2-S5. The unmodified and non-imbibed cross-linked beads show a small calcium signature that likely originates from the deacetylation process from the as-received commercial 
product. Imbibing beads with calcium resulted in a more pronounced calcium signature that further support the role of cation coordination onto the bead surface. A small but appreciable nitrogen signature appeared after cross-linking with glutaraldehyde, where a peak shift occurs upon calcium imbibing that signifies a change in coordination environment due to the presence of glutaraldehyde.

\subsection{Sulfate Adsorption Results}

Phase-inversion synthesis of chitosan beads with subsequent cross-linking and metal ion imbibing results in the incorporation of $\mathrm{Ca}^{2+}$ species onto the bead surface. Modular synthesis of this type was shown to result in enhanced uptake properties of organophosphates, as compared with unmodified bead systems [26]. By analogy, incremental sulfate adsorption properties are posited for materials prepared via the modular design approach (cf. Figure 1). The adsorption isotherm Sips modeling [60] results for sulfate were obtained by the turbidity method [61] The trends in the adsorption of sulfate uptake reveal how the modular synthesis of chitosan beads relate to the incremental variation in the sulfate adsorption properties (cf. Supplementary Table S1). In Figure 5, the adsorption isotherms illustrate trends in the sulfate adsorption that relate to the role of chemical modification of the bead systems at conditions relevant to ground water environments.
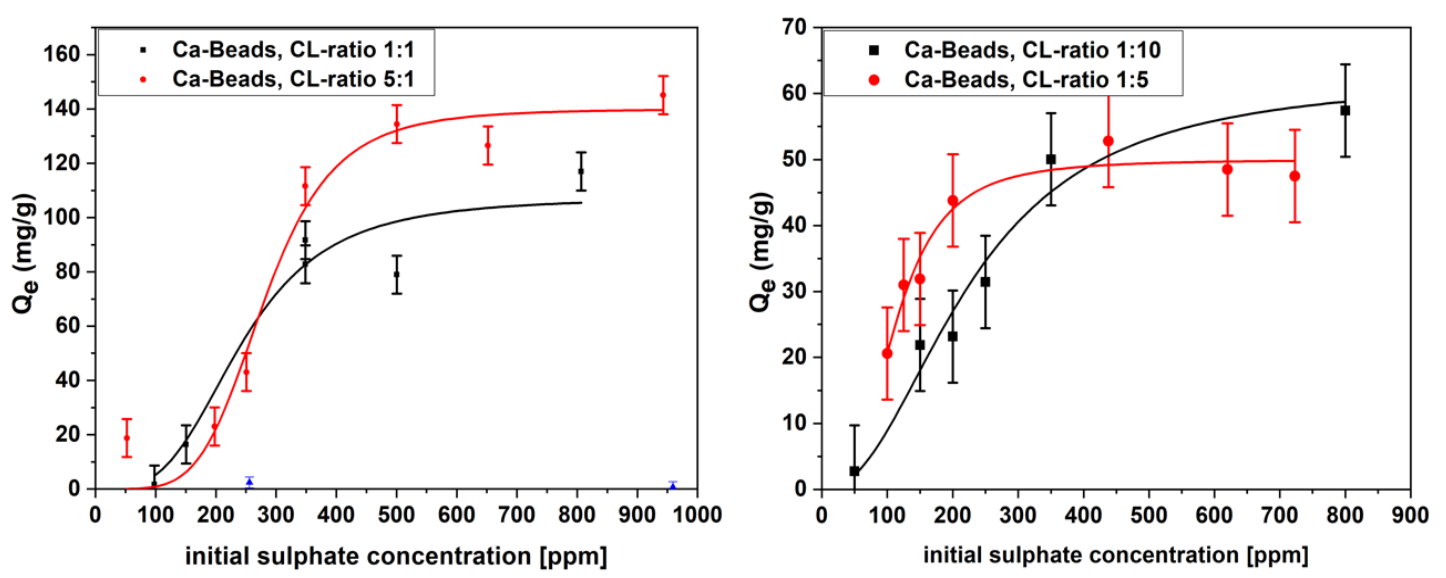

Figure 5. Sulfate adsorption isotherms with cross-linked and calcium imbibed beads (CL-ratio of 1:1 and 5:1 on the left, CL-ratio of 1:5 and 1:10 on the right (for beads with CL-ratio 1:15, see Figure S6 in the supplementary materials) at pH 5 and $295 \mathrm{~K}$. The solid lines are the best-fit according to the Sips isotherm model (cf. Equation (2)).

The adsorption isotherm results reveal that the beads efficiently remove sulfate from aqueous solution at levels below $1000 \mathrm{ppm}$, where the overall adsorption capacity scales with the initial sulfate concentration. Although the bead systems exhibit reduced swelling behavior with increased cross-linking, the uptake capacity increases with greater cross-linking, further highlighting the primary role of adsorption sites at the chitosan bead surface. This trend parallels that for the dye adsorption results of PNP (cf. Table 1). By contrast, the negligible role of mass transfer of sulfate into the bead core due to diffusion effects can be inferred from confocal microscopy results of anionic dyes with chitosan beads reported elsewhere [58]. Thus, the adsorption sites within the bead core for such systems is inferred to play a secondary role in sulfate adsorption. The uptake reached a maximum of ca. $140 \mathrm{mg} / \mathrm{g}$ with the 5:1 cross-linked and calcium-imbibed material, further supporting the key (primary) role of the bead surface adsorption sites for sulfate. This trend concurs with the formation of imine surface sites and their key role in anion uptake properties [62], in parallel agreement with the dye adsorption results presented in Table 1. Whereas the main contributions of the modified beads are concluded to occur mainly at the bead surface sites of the modified chitosan, secondary adsorption of sulfate in the chitosan bead core contribute less due to limited adsorbate diffusion. A similar binding mode for sulfate uptake is proposed, as reported elsewhere [63] for the adsorption of urea by $\mathrm{Cu}$ (II) imbibed 
form of chitosan (cf. Scheme 1 in [63]). The observed trend in sulfate uptake relates to glutaraldehyde cross-linking, as evidenced by the reduced bead swelling, since incremental cross-linking is inferred to contribute to reduced bead expansion. The incremental formation of imine linkages on the bead surface favor anion adsorption due to the basicity (greater $\mathrm{pK}_{\mathrm{a}}$ value) of imine groups upon cross-linking of chitosan. The creation of unique imine surface adsorption sites through the modular synthesis reported herein is inferred to result in a modified bead surface upon cross-linking of chitosan, along with pillaring of the bead network to allow for the chelation of $\mathrm{Ca}^{2+}$ at the bead periphery [54].

The adsorption studies revealed a strong correlation of adsorption capacity with the surface adsorption sites and the textural properties of the beads. The attenuated diffusion within the bead core and limited swelling of the cross-linked beads provide support that surface adsorption sites play a key role. This finding correlates with the adsorption capacity and limited accessible surface area of the beads, as compared with adsorbents in a powdered form [64,65]. Restricted diffusion at the core domains of the bead is supported by the kinetics of sulfate adsorption for a model bead system (cf. Supplementary Figure S7). In addition, the heterogeneity factor $n$ of the bead materials concerning sulfate uptake increased (cf. Supplementary Table S2). This heterogeneity parameter (n) further supports that multiple adsorption sites contribute to the overall uptake of sulfate in this system. In conjunction with the kinetic results (cf. Supplementary Figure S7), the presence of multiple adsorption sites is supported by the best-fit results provided by the pseudo-second order kinetic model. The offset in uptake between beads versus powders relates to the greater accessible surface area of powder materials, in agreement with the sulfate $Q_{m}$ values for select adsorbent materials from the literature (cf. Table 2). While sodium sulfate has a favorable water solubility, sulfate displays lower affinity towards chitosan than other oxyanions such as vanadium (III) oxide $\left(\mathrm{V}_{2} \mathrm{O}_{3}\right)$. The greater uptake of $\mathrm{V}_{2} \mathrm{O}_{3}$ may relate to its less negative Gibbs energy of hydration, in line with its lower water solubility (ca. $0.1 \mathrm{~g} / \mathrm{L}$ ) [66] versus sodium sulfate (ca. $140 \mathrm{~g} / \mathrm{L}$ ). In another study, the simultaneous uptake of $\mathrm{Cu}^{2+}$ and sulfate anions onto different forms of cellulose was noted, where significant uptake occurs as $\mathrm{Cu}^{2+}$ chelates with the electron-rich domains of cellulose. Thereafter, sulfate is co-adsorbed due to charge neutralization and complexation effects [67].

Table 2. Literature comparison of the sulfate monolayer uptake capacity $\left(\mathrm{Q}_{\mathrm{m}}\right)$ values for different sorbent materials and results from this study.

\begin{tabular}{|c|c|c|c|}
\hline Material & $\begin{array}{c}\mathrm{SO}_{4}{ }^{2-} \text { Uptake } \\
\mathrm{Q}_{\mathrm{m}}(\mathrm{mg} / \mathrm{g})\end{array}$ & Concentration (ppm) & Conditions \\
\hline $\begin{array}{l}\text { Cross-linked } \\
\text { chitosan beads } \\
\text { (This study)* }\end{array}$ & 35 & $\mathrm{C}_{0}=1000 \mathrm{ppm}$ & $\begin{array}{c}\text { CL-ratio 1:15 } \\
\mathrm{Ca}^{2+} \text {-imbibed } \\
\text { pH } 5\end{array}$ \\
\hline $\begin{array}{l}\text { Cross-linked } \\
\text { chitosan beads } \\
\text { (This study)* }\end{array}$ & 140 & $\mathrm{C}_{0}=1000 \mathrm{ppm}$ & $\begin{array}{c}\text { CL-ratio 5:1 } \\
\text { Ca }^{2+} \text {-imbibed } \\
\text { pH 5 } 5\end{array}$ \\
\hline $\mathrm{ZnCl}_{2}$ modified zeolite & 38 & $\mathrm{C}_{0}=1000 \mathrm{ppm}$ & $\begin{array}{l}\text { CTAB modified } \\
40{ }^{\circ} \mathrm{C}\end{array}$ \\
\hline $\begin{array}{l}\text { Pyrrole modified activated carbon } \\
\qquad[69]\end{array}$ & 45 & $\mathrm{C}_{0}=250 \mathrm{ppm}$ & $\mathrm{pH} 7$ \\
\hline $\begin{array}{l}\text { Modified Rice Straw } \\
{[70]}\end{array}$ & 75 & $C_{0}=500 \mathrm{ppm}$ & $\mathrm{pH} 6.4$ \\
\hline $\begin{array}{c}\text { Poly( } m \text {-phenylendiamine }) \\
{[71]}\end{array}$ & 109 & & $\mathrm{pH}<3$ \\
\hline Chitin & 150 & $\mathrm{C}_{0}=1200 \mathrm{ppm}$ & $\begin{array}{c}\mathrm{pH} 4.3 \\
10 \mathrm{~g} / \mathrm{L} \text { sorbent }\end{array}$ \\
\hline $\begin{array}{l}\text { Chitosan } \\
\text { [72] }\end{array}$ & 210 & $\mathrm{C}_{0}=2500 \mathrm{ppm}$ & $\mathrm{Fe}(\mathrm{II}) \mathrm{SO}_{4}$ \\
\hline $\begin{array}{l}\text { CC/QAC } \\
\text { [67] }\end{array}$ & 526 & & $\mathrm{pH} 5 ; \mathrm{CuSO}_{4}$ \\
\hline
\end{tabular}

CC/QAC refers to Carboxylate Cellulose/Quarternised Cellulose. * Denotes results obtained in this study 


\subsection{Bead Regeneration Studies}

Previous reports indicate that biopolymer adsorbents may undergo loss of adsorption capacity after multiple cycles of adsorption-desorption. A key feature of sustainable adsorbent technology relates to a near constant level of removal efficiency after regeneration, along with minor susceptibility to degradation over time. Thus, the most promising bead material (5:1 calcium imbibed system) was evaluated for its sulfate adsorption-desorption properties. Sodium chloride solution is a viable agent for sulfate desorption, however, in case of the weakly coordinated $\mathrm{Ca}^{2+}$ species, competitive $\mathrm{Na}^{+}$binding effects may lead to calcium leaching. To assess this effect, two $\mathrm{Ca}^{2+}$ imbibed bead systems (1:1 and 5:1 cross-linked systems) were tested using $\mathrm{NaCl}$ solution as the regenerant. Therefore, the supernatant was tested for $\mathrm{Ca}^{2+}$ leachate with Eriochrome Black $\mathrm{T}$ as the indicator [73]. Both the 5:1 and 1:1 systems showed some leaching, whereas the 1:1 system was less evident. To address leaching effects, the regeneration of beads used $0.1 \mathrm{M} \mathrm{CaCl}_{2}$ solution as an alternative regenerant media. The results for the 5:1 cross-linked bead material are presented in Figure 6. Prior to cycle 1 (cf. Figure 6), the regeneration studies required soaking of the beads for $24 \mathrm{~h}$ in Millipore water. The beads were then added to the sulfate solution (1000 ppm), where six cycles of regeneration were carried out. In general, a slight increase occurs from the first to the last cycle, indicating that these bead systems have good stability overall across multiple cycles of regeneration, according to the reported standard errors. A precedence for the regeneration method reported in Figure 6 finds support in a fixed-bed column study reported by Solgi et al. [74]. Therein, the recyclability of chitosan materials using aqueous $\mathrm{CaCl}_{2}$ revealed reproducible sulfate adsorption over multiple cycles of adsorption-desorption.

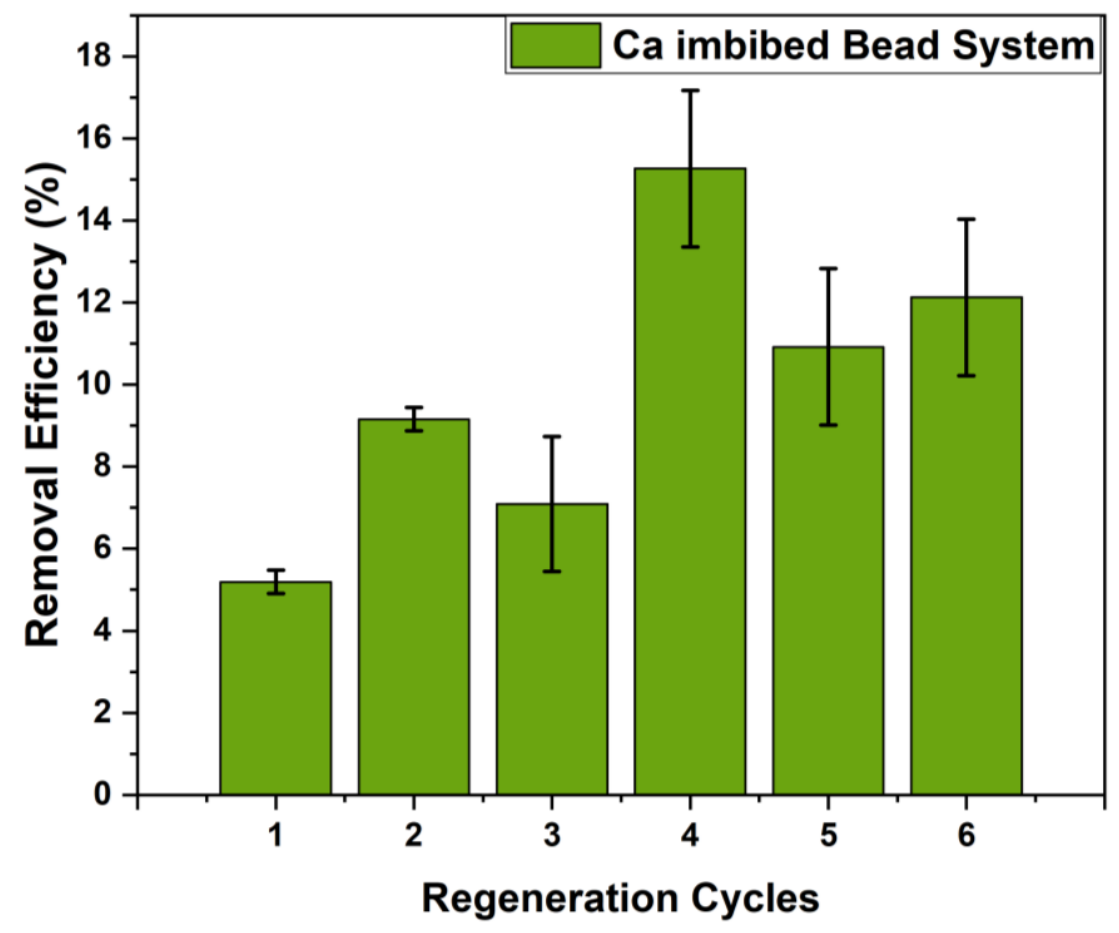

Figure 6. Removal efficiency of 5:1 cross-linked, calcium-imbibed bead systems with ca. $1000 \mathrm{ppm}$ sulfate solution at $\mathrm{pH} 4-5$ over 6 adsorption/desorption cycles and regeneration in $0.1 \mathrm{M} \mathrm{CaCl}_{2}$-solution.

\section{Materials and Methods}

\subsection{Materials}

$\mathrm{CaCl}_{2}, \mathrm{BaCl}_{2}, \mathrm{FeCl}_{3}$, glutaraldehyde (GA), EDTA, low-molecular-weight chitosan (75-85\% deacetylation with a molecular weight range of 50,000-190,000 Da), $\mathrm{KBr}$ (IR Grade), and $\mathrm{NaCl}$ (ACS grade) were obtained from Sigma Aldrich Canada (Oakville, Ontario, Canada). Glacial acetic 
acid, $\mathrm{HCl}(a q) 37 \%, \mathrm{NaOH}$, and $\mathrm{Na}_{2} \mathrm{SO}_{4}$ were obtained from Fisher Chemical (Fisher Scientific, Geel, Belgium). Eriochrome Black T and $p$-nitrophenol (PNP) were purchased from Alfa Aesar (Alfa Aesar, Tewksbury, MA, USA), anhydrous sodium carbonate and $\mathrm{NH}_{4} \mathrm{Cl}$ were purchased from EMD (by Merck, Darmstadt, Germany). All chemicals were used as received unless specified otherwise. Millipore water (18.2 $\mathrm{MOhm} \mathrm{cm}^{-1}$ Resistance) was used for the preparation of all solutions.

\subsubsection{Synthesis of Cross-Linked Chitosan Beads}

Briefly, chitosan powder $(5 \mathrm{~g})$ was dissolved at $22{ }^{\circ} \mathrm{C}$ overnight in $250 \mathrm{~mL} \%$ (v/v) acetic acid solution and then added dropwise using a volumetric burette with gentle stirring into a $0.5 \mathrm{M} \mathrm{NaOH}$ solution $(250 \mathrm{~mL})$. After complete addition, the stirring was stopped, and the beads material were left to neutralize under quiescent conditions for at least $16 \mathrm{~h}$ at $22^{\circ} \mathrm{C}$ to afford stabilization of the beads after the phase-inversion process. The beads were rinsed with deionized water until the washings reached a neutral $\mathrm{pH}$. The required amount of glutaraldehyde was calculated based on the desired stoichiometric molar ratio and the requisite volume of glutaraldehyde solution was added to the beads at $\mathrm{pH}$ 7. Thus, a 5:1 ratio corresponds to 5 moles glutaraldehyde to 1 mol of glucosamine monomers of chitosan. Sufficient water was added to submerge the beads to carry out the reaction for $48 \mathrm{~h}$ at $23^{\circ} \mathrm{C}$. Thereafter, the beads were washed with copious amounts of water and imbibed in fresh water for $48 \mathrm{~h}$ with repeated exchange of water to allow efficient removal of unreacted glutaraldehyde. The beads were either dried at $40^{\circ} \mathrm{C}$ for $48 \mathrm{~h}$ or used without drying for subsequent calcium-imbibing, followed by drying at $40^{\circ} \mathrm{C}$ for 2 days.

\subsubsection{Calcium Doping}

The beads were imbibed in excess volume of aqueous $\mathrm{CaCl}_{2}(0.1 \mathrm{M})$ for $48 \mathrm{~h}$ at $22{ }^{\circ} \mathrm{C}$ under quiescent conditions.

\subsection{Methods}

\subsubsection{Materials Characterization}

The weight loss profiles were obtained using a Q50 TA Instruments (New Castle, DE, USA) thermogravimetric analyzer (TGA) with a weighing precision of $0.01 \%$ and a temperature precision of $0.1^{\circ} \mathrm{C}$ for isothermal conditions. Samples were heated in open aluminum pans at $30^{\circ} \mathrm{C}$ for $5 \mathrm{~min}$ to enable equilibration prior to heating at $5{ }^{\circ} \mathrm{C} / \mathrm{min}$ to $500{ }^{\circ} \mathrm{C}$. The PZC measurement is based on the $\mathrm{pH}$ shift method, where solutions $(25 \mathrm{~mL})$ at several different $\mathrm{pH}$ (ca. $2,4,5,8,10)$ values were used with the addition of chitosan beads (ca. $60 \mathrm{mg}$ ). After mixing for $48 \mathrm{~h}$ at $22{ }^{\circ} \mathrm{C}$ to allow for equilibration, the $\mathrm{pH}$ of each solution was re-measured (with a Mettler Toledo Seven Compact and accumet probe with accuracy of $\mathrm{pH} \pm 0.2$; Mettler Toledo, Mississauga, ON, Canada) and the PZC was determined by calculation of the intersection of the plotted lines of initial vs. final $\mathrm{pH}$ [75]. Solids ${ }^{13} \mathrm{C}$ NMR spectra were obtained using a wide-bore $(89 \mathrm{~mm}) 8.6 \mathrm{~T}$ Oxford superconducting magnet system with a $4 \mathrm{~mm}$ rotor that used cross-polarization conditions with magic angle spinning (CP-MAS) during acquisition. Topspin 1.3 (Bruker Bio Spin, Billerica, MA, USA) was used for the control of acquisition and data processing parameters. Determination of the sulfate concentration was carried out via UV-Vis-based turbidity spectrophotometric measurement that employs $\mathrm{BaCl}_{2}$ (Indian Standard IS 3025) with a Thermoscientific Spectronic 200e (Ottawa, ON, Canada). All X-ray Photoelectron Spectroscopy (XPS) measurements were acquired using a Kratos (Manchester, UK) AXIS Supra system. This system is equipped with a $500 \mathrm{~mm}$ Rowland circle monochromated $\mathrm{Al} \mathrm{K}-\alpha(1486.6 \mathrm{eV})$ source and a combined hemi-spherical analyzer (HSA) with a spherical mirror analyzer (SMA). A spot size of hybrid slot (300 $\times 700$ microns) was used. All survey scan spectra were collected in the -5-1200 binding energy range in $1 \mathrm{eV}$ steps with a pass energy of $160 \mathrm{eV}$. An accelerating voltage of $15 \mathrm{keV}$ and an emission current of $15 \mathrm{~mA}$ was used for the analysis. Solvent swelling was estimated gravimetrically by fully soaking the bead materials in Millipore water for $24 \mathrm{~h}$, where excess solvent was removed from 
the bead surface by tamping dry with tissue paper. The residual of bound water within the swollen beads was removed upon drying until no further weight loss was measured. The swelling capacity was calculated by the dry weight value $(100 \%)$ vs. the wet weight after soaking.

Surface area was estimated using $p$-nitrophenol (PNP), where a $5 \mathrm{mM} \mathrm{PNP} \mathrm{solution} \mathrm{was} \mathrm{prepared}$ in $0.1 \mathrm{M}$ carbonate buffer at $\mathrm{pH} 8.4 \pm 0.2$ to yield the anion form of PNP. The bead systems (ca. $15 \mathrm{mg}$ ) were added to $10 \mathrm{~mL}$ of $5 \mathrm{mM}$ PNP solution at $22^{\circ} \mathrm{C}$ and shaken for $24 \mathrm{~h}$ (Scilogex SK-0330-Pro, Scilogex, Rocky Hill, CT, USA). UV-vis absorbance measurements for concentration determination was carried out at the isosbestic point of the spectral profile of PNP to avoid pH-dependent intensity variations.

\subsubsection{Adsorption Studies}

Approximately $10 \mathrm{mg}$ of adsorbent was added to a stock sulfate solution $(10 \mathrm{~mL})$ with a known concentration (ca. 50 to $1000 \mathrm{ppm}$ ). The $\mathrm{pH}$ of the solution was adjusted to $\mathrm{pH} 5$ with hydrochloric acid solution. The samples were equilibrated at $22^{\circ} \mathrm{C}$ for $24 \mathrm{~h}$ with constant shaking (Scilogex SK-0330-Pro). The difference in concentration $\left(\mathrm{C}_{0}-\mathrm{C}_{\mathrm{e}}\right)$ before and after the adsorption process was used to calculate $\mathrm{Q}_{\mathrm{e}}$ (cf. Equation (2)). The sulfate concentration was determined via turbidity measurements (Indian Standard IS 3025 Part 24, 4, re-affirmed 2009) with $\mathrm{BaCl}_{2}$ and conditioning reagent (2) at $420 \mathrm{~nm}$. The Sips model (sometimes referred to as Langmuir-Freundlich isotherm) was used to evaluate the isotherm profile and, depending on the exponent term $(1 / n)$, it may converge either to the Freundlich (approaching zero) or to the Langmuir model (approaching unity) [60].

$$
\mathrm{Q}_{\mathrm{e}}=\frac{\mathrm{Q}_{\mathrm{m}} \mathrm{a}_{\mathrm{s}} \mathrm{C}_{\mathrm{e}}^{1 / n}}{1+\mathrm{a}_{\mathrm{s}} \mathrm{C}_{\mathrm{e}}^{1 / n}}
$$

The parameters in Equation (2) are defined as follows: $Q_{m}$ is the monolayer adsorption capacity $(\mathrm{mg} / \mathrm{g}), \mathrm{a}_{\mathrm{s}}$ is the Sips constant, and $1 / n$ is the index heterogeneity of the sorbent material.

\subsubsection{Calcium Leaching}

To test for calcium leaching in the sample solution, a sample solution $(5-10 \mathrm{~mL})$ was added to $25 \mathrm{~mL}$ water, $5 \mathrm{~mL} \mathrm{NH}_{4} \mathrm{Cl} / \mathrm{NH}_{4} \mathrm{OH}$ buffer (4 M, pH between 10.2-10.4) with a few drops of Eriochrome Black $\mathrm{T}$ indicator added. Titration with EDTA solution was done until a color change occurred at the end-point [73].

\subsubsection{Bead Regeneration Studies}

Adsorption and regeneration cycles were carried out by pre-swelling the beads in Millipore water to ensure equilibrium conditions and eliminate inconsistent swelling behavior. The respective beads were transferred into the appropriate solutions (1000 ppm sulfate solution for adsorption; $0.1 \mathrm{M} \mathrm{CaCl}_{2}$ solution for bead regeneration) after washing and quick removal of excess water by tamping dry with filter paper.

\subsubsection{Bead Size Determination}

Bead size determination was estimated using a digital caliper with a bead sample size of $n=15$ per system.

\section{Conclusions}

Herein, several types of chitosan bead systems were prepared using a modular synthetic design strategy (cf. Figure 1) that involves phase-inversion synthesis along with glutaraldehyde cross-linking at variable levels with sequential surface modification via bead doping with $\mathrm{Ca}^{2+}$ in aqueous calcium chloride. Complementary characterization of the bead systems was carried out using ${ }^{13} \mathrm{C}$ NMR spectroscopy, XPS, and thermal analysis to provide complementary support of variable cross-linking and $\mathrm{Ca}^{2+}$ imbibing. Cross-linking of chitosan beads was achieved using excess stoichiometric levels of 
glutaraldehyde, where the cross-linker content correlates with the solvent swelling and dye adsorption properties of the biopolymer network. The sulfate adsorption isotherm results revealed that greater uptake occurred upon incremental cross-linking, along with $\mathrm{Ca}^{2+}$ imbibition. This approach finds support in other work, albeit with other metal-oxyanion $\left(\mathrm{CrO}_{4}{ }^{2-}\right)$ systems and with variable types of co-adsorbed cation species [35,43-46]. The sustainability of the chitosan-based adsorbent materials prepared herein was demonstrated with the use of a modular green design and facile approach. Recyclability of beads was shown using a salt-based regenerant $\left(\mathrm{CaCl}_{2}\right)$ solution over multiple cycles of adsorption-desorption to mitigate potential leaching effects of calcium from the bead system. Further work is underway to scale-up the process for water treatment applications that will focus on the controlled removal of oxyanions under dynamic conditions relevant to food, pharmaceuticals, and nutraceuticals applications [76].

Supplementary Materials: Supplementary materials can be found at http://www.mdpi.com/1422-0067/21/19/ 7130/s1.

Author Contributions: Conceptualization, L.D.W.; methodology, B.G.K.S. and L.D.W.; validation, B.G.K.S. and L.D.W.; formal analysis, B.G.K.S.; investigation, B.G.K.S.; resources, L.D.W.; data curation, B.G.K.S.; writing-original draft preparation, B.G.K.S.; writing-review and editing, B.G.K.S. and L.D.W.; visualization, B.G.K.S.; supervision, L.D.W.; project administration, L.D.W.; funding acquisition, L.D.W. All authors have read and agreed to the published version of the manuscript.

Funding: This research was funded by Government of Saskatchewan (Ministry of Agriculture and the Canadian Agriculture Partnership), through the Agricultural Development Fund (Project \# 20170247) and partial financial support provided by Saskmilk (Contract \# 348827). The APC was funded by MDPI as part of a special invitation to the corresponding author.

Acknowledgments: B.G.K.S. kindly acknowledges the academic support provided by Eric Moore and Anna Hogan from the University College Cork, Ireland. Helpful discussions and guidance provided by Mohamed H. Mohamed are gratefully acknowledged.

Conflicts of Interest: The authors declare no conflict of interest.

\section{Abbreviations}

$\begin{array}{ll}\text { CL } & \text { Cross-linking } \\ \text { NMR } & \text { Nuclear Magnetic Resonance } \\ \text { TGA } & \text { Thermogravimetric Analysis } \\ \text { XPS } & \text { X-ray Photoelectron Spectroscopy }\end{array}$

\section{References}

1. Sharma, M.K.; Kumar, M. Sulphate Contamination in Groundwater and Its Remediation: An Overview. Environ. Monit. Assess. 2020, 192, 74. [CrossRef] [PubMed]

2. Moreno-Casas, P.; Vecchio-Sadus, A.; Aral, H. Environmental Impact and Toxicology of Sulphate; Enviromine: Santiago, Chile, 2009; pp. 1-10.

3. Sulfate in Drinking-Water. Available online: https://www.who.int/water_sanitation_health/dwq/chemicals/ sulfate.pdf (accessed on 25 September 2020).

4. Bashir, M.T.; Ali, S.; Bashir, A. Health Effects from Exposure to Sulphates and Chlorides in Drinking Water. Pak. J. Med. Health Sci. 2012, 6, 648-652.

5. Environmental Protection Agency. Drinking Water Advisory: Consumer Acceptability Advice and Health Effects Analysis Drinking Water Advisory. Available online: https:/www.epa.gov/sites/production/files/ 2014-09/documents/support_cc1_sodium_dwreport.pdf (accessed on 25 September 2020).

6. Cañedo-Argüelles, M.; Kefford, B.J.; Piscart, C.; Prat, N.; Schäfer, R.B.; Schulz, C.-J. Salinisation of Rivers: An Urgent Ecological Issue. Environ. Pollut. 2013, 173, 157-167. [CrossRef] [PubMed]

7. Feist, M.; Elford, C.; Bailey, P.; Campbell, J. A Review of Dugout and Well Water Tested for Livestock Quality in Southern Saskatchewan. Available online: http://publications.gov.sk.ca/documents/20/106044-Technical\% 20Report\%20on\%20South\%20Saskatchewan\%20Water\%20Quality\%20-\%20March\%202018.pdf (accessed on 25 September 2020). 
8. Cederkvist, K.; Holm, P.E.; Jensen, M.B. Full-Scale Removal of Arsenate and Chromate from Water Using a Limestone and Ochreous Sludge Mixture as a Low-Cost Sorbent Material. Water Environ. Res. 2010, 82, 401-408. [CrossRef]

9. Lee, D.J.; Liu, X.; Weng, H.L. Sulfate and Organic Carbon Removal by Microbial Fuel Cell with SulfateReducing Bacteria and Sulfide-Oxidising Bacteria Anodic Biofilm. Bioresour. Technol. 2014, 156, 14-19. [CrossRef]

10. Darbi, A.; Viraraghavan, T.; Jin, Y.-C.; Braul, L.; Corkal, D. Sulfate Removal from Water. Water Qual. Res. J. 2003, 38, 169-182. [CrossRef]

11. Bódalo, A.; Gómez, J.L.; Gómez, E.; León, G.; Tejera, M. Sulfonated Polyethersulfone Membranes in the Desalination of Aqueous Solutions. Desalination 2004, 168, 277-282. [CrossRef]

12. Guerrero-Flores, A.D.; Uribe-Salas, A.; Dávila-Pulido, G.I.; Flores-Álvarez, J.M. Simultaneous Removal of Calcium and Sulfate Ions from Flotation Water of Complex Sulfides. Miner. Eng. 2018, 123, 28-34. [CrossRef]

13. Bowell, R.J.; Dill, S.; Cowan, J.; Wood, A. A Review of Sulfate Removal Options for Mine Waters. In Mine Water 2004-Proceedings International Mine Water Association Symposium 2; Jarvis, A.P., Dudgeon, B.A., Younger, P.L., Eds.; University of Newcastle: Newcastle upon Tyne, UK, 2004; pp. 329-342.

14. Fernando, W.A.M.; Ilankoon, I.M.S.K.; Syed, T.H.; Yellishetty, M. Challenges and Opportunities in the Removal of Sulphate Ions in Contaminated Mine Water: A Review. Miner. Eng. 2018, 117, 74-90. [CrossRef]

15. Runtti, H.; Tolonen, E.-T.; Tuomikoski, S.; Luukkonen, T.; Lassi, U. How to Tackle the Stringent Sulfate Removal Requirements in Mine Water Treatment-A Review of Potential Methods. Environ. Res. 2018, 167, 207-222. [CrossRef]

16. Singh, N.B.; Nagpal, G.; Agrawal, S.; Rachna. Water Purification by Using Adsorbents: A Review. Environ. Technol. Innov. 2018, 11, 187-240. [CrossRef]

17. Ahmed, S.; Ikram, S. Chitosan: Derivatives, Composites and Applications; Scrivener Publishing: Beverly, MA, USA, 2017. [CrossRef]

18. Pillai, C.K.S.; Paul, W.; Sharma, C.P. Chitin and Chitosan Polymers: Chemistry, Solubility and Fiber Formation. Prog. Polym. Sci. 2009, 34, 641-678. [CrossRef]

19. Gao, X.; Zhang, H.; Chen, K.; Zhou, J.; Liu, Q. Removal of Heavy Metal and Sulfate Ions by Cellulose Derivative-Based Biosorbents. Cellulose 2018, 25, 2531-2545. [CrossRef]

20. Ji, J.; Wang, L.; Yu, H.; Chen, Y.; Zhao, Y.; Zhang, H.; Amer, W.A.; Sun, Y.; Huang, L.; Saleem, M. Chemical Modifications of Chitosan and Its Applications. Polym. Plast. Technol. Eng. 2014, 53, 1494-1505. [CrossRef]

21. Vold, I.M.N.; Vårum, K.M.; Guibal, E.; Smidsrød, O. Binding of Ions to Chitosan-Selectivity Studies. Carbohydr. Polym. 2003, 54, 471-477. [CrossRef]

22. Tolaimate, A.; Desbrières, J.; Rhazi, M.; Alagui, A.; Vincendon, M.; Vottero, P. On the Influence of Deacetylation Process on the Physicochemical Characteristics of Chitosan from Squid Chitin. Polymer 2000, 41, 2463-2469. [CrossRef]

23. Marpu, S.; Benton, E. Shining Light on Chitosan: A Review on the Usage of Chitosan for Photonics and Nanomaterials Research. Int. J. Mol. Sci. 2018, 19, 1795. [CrossRef]

24. Kyzas, G.Z.; Bikiaris, D.N.; Lazaridis, N.K. Low-Swelling Chitosan Derivatives as Biosorbents for Basic Dyes. Langmuir 2008, 24, 4791-4799. [CrossRef]

25. Kildeeva, N.R.; Perminov, P.A.; Vladimirov, L.V.; Novikov, V.V.; Mikhailov, S.N. About Mechanism of Chitosan Cross-Linking with Glutaraldehyde. Russ. J. Bioorg. Chem. 2009, 35, 360-369. [CrossRef]

26. Mahaninia, M.H.; Wilson, L.D. Cross-Linked Chitosan Beads for Phosphate Removal from Aqueous Solution. J. Appl. Polym. Sci. 2016, 133, 42949. [CrossRef]

27. Mahaninia, M.H.; Wilson, L.D. Modular Cross-Linked Chitosan Beads with Calcium Doping for Enhanced Adsorptive Uptake of Organophosphate Anions. Ind. Eng. Chem. Res. 2016, 55, 11706-11715. [CrossRef]

28. Varma, A.; Deshpande, S.; Kennedy, J. Metal Complexation by Chitosan and Its Derivatives: A Review. Carbohydr. Polym. 2004, 55, 77-93. [CrossRef]

29. Kwok, K.C.M.; Koong, L.F.; Al Ansari, T.; McKay, G. Adsorption/Desorption of Arsenite and Arsenate on Chitosan and Nanochitosan. Environ. Sci. Pollut. Res. 2018, 25, 14734-14742. [CrossRef] [PubMed]

30. Padilla-Rodríguez, A.; Hernández-Viezcas, J.A.; Peralta-Videa, J.R.; Gardea-Torresdey, J.L.; Perales-Pérez, O.; Román-Velázquez, F.R. Synthesis of Protonated Chitosan Flakes for the Removal of Vanadium(III, IV and V) Oxyanions from Aqueous Solutions. Microchem. J. 2015, 118, 1-11. [CrossRef] 
31. Wan Ngah, W.S.; Teong, L.C.; Hanafiah, M.A.K.M. Adsorption of Dyes and Heavy Metal Ions by Chitosan Composites: A Review. Carbohydr. Polym. 2011, 83, 1446-1456. [CrossRef]

32. Mende, M.; Schwarz, D.; Steinbach, C.; Boldt, R.; Schwarz, S. Simultaneous Adsorption of Heavy Metal Ions and Anions from Aqueous Solutions on Chitosan-Investigated by Spectrophotometry and SEM-EDX Analysis. Colloids Surf. A Physicochem. Eng. Asp. 2016, 510, 275-282. [CrossRef]

33. Crini, G. Non-Conventional Low-Cost Adsorbents for Dye Removal: A Review. Bioresour. Technol. 2006, 97, 1061-1085. [CrossRef]

34. Pal, A.; Pan, S.; Saha, S. Synergistically Improved Adsorption of Anionic Surfactant and Crystal Violet on Chitosan Hydrogel Beads. Chem. Eng. J. 2013, 217, 426-434. [CrossRef]

35. Miretzky, P.; Cirelli, A.F. Fluoride Removal from Water by Chitosan Derivatives and Composites: A Review. J. Fluor. Chem. 2011, 132, 231-240. [CrossRef]

36. Preethi, J.; Meenakshi, S. Fabrication of $\mathrm{La}^{3+}$ Impregnated Chitosan/ $\beta$-Cyclodextrin Biopolymeric Materials for Effective Utilization of Chromate and Fluoride Adsorption in Single Systems. J. Chem. Eng. Data 2018, 63, 723-731. [CrossRef]

37. Bacelo, H.; Pintor, A.M.A.; Santos, S.C.R.; Boaventura, R.A.R.; Botelho, C.M.S. Performance and Prospects of Different Adsorbents for Phosphorus Uptake and Recovery from Water. Chem. Eng. J. 2020, 381, 122566. [CrossRef]

38. Vikrant, K.; Kim, K.-H.; Ok, Y.S.; Tsang, D.C.W.; Tsang, Y.F.; Giri, B.S.; Singh, R.S. Engineered/Designer Biochar for the Removal of Phosphate in Water and Wastewater. Sci. Total Environ. 2018, 616-617, 1242-1260. [CrossRef]

39. Yin, Q.; Zhang, B.; Wang, R.; Zhao, Z. Biochar as an Adsorbent for Inorganic Nitrogen and Phosphorus Removal from Water: A Review. Environ. Sci. Pollut. Res. 2017, 24, 26297-26309. [CrossRef]

40. Liu, R.; Chi, L.; Wang, X.; Sui, Y.; Wang, Y.; Arandiyan, H. Review of Metal (Hydr)Oxide and Other Adsorptive Materials for Phosphate Removal from Water. J. Environ. Chem. Eng. 2018, 6, 5269-5286. [CrossRef]

41. Preethi, J.; Vigneshwaran, S.; Meenakshi, S. Performance of Chitosan Engraved Iron and Lanthanum Mixed Oxyhydroxide for the Detoxification of Hexavalent Chromium. Int. J. Biol. Macromol. 2019, 130, 491-498. [CrossRef] [PubMed]

42. Wang, J.; Zhuang, S. Removal of Various Pollutants from Water and Wastewater by Modified Chitosan Adsorbents. Crit. Rev. Environ. Sci. Technol. 2017, 47, 2331-2386. [CrossRef]

43. Yang, W.; Tang, Q.; Dong, S.; Chai, L.; Wang, H. Single-Step Synthesis of Magnetic Chitosan Composites and Application for Chromate (Cr(VI)) Removal. J. Cent. South Univ. 2016, 23, 317-323. [CrossRef]

44. Ferrero, F.; Tonetti, C.; Periolatto, M. Adsorption of Chromate and Cupric Ions onto Chitosan-Coated Cotton Gauze. Carbohydr. Polym. 2014, 110, 367-373. [CrossRef]

45. Moghaddam, A.Z.; Esmaeilkhanian, E.; Shakourian-Fard, M. Immobilizing Magnetic Glutaraldehyde Cross-Linked Chitosan on Graphene Oxide and Nitrogen-Doped Graphene Oxide as Well-Dispersible Adsorbents for Chromate Removal from Aqueous Solutions. Int. J. Biol. Macromol. 2019, 128, 61-73. [CrossRef] [PubMed]

46. Mishima, K.; Du, X.; Sekiguchi, S.; Kano, N. Experimental and Theoretical Studies on the Adsorption and Desorption Mechanisms of Chromate Ions on Cross-Linked Chitosan. J. Funct. Biomater. 2017, 8, 51. [CrossRef] [PubMed]

47. Sarmento, B.; Ribeiro, A.; Veiga, F.; Ferreira, D. Development and Characterization of New Insulin Containing Polysaccharide Nanoparticles. Colloids Surf. B Biointerfaces 2006, 53, 193-202. [CrossRef]

48. Agiba, A.M.; Nasr, M.; Abdel-Hamid, S.; Eldin, A.B.; Geneidi, A.S. Enhancing the Intestinal Permeation of the Chondroprotective Nutraceuticals Glucosamine Sulphate and Chondroitin Sulphate Using Conventional and Modified Liposomes. Curr. Drug Deliv. 2018, 15, 907-916. [CrossRef]

49. Chaiyasan, W.; Srinivas, S.P.; Tiyaboonchai, W. Crosslinked Chitosan-Dextran Sulfate Nanoparticle for Improved Topical Ocular Drug Delivery. Mol. Vis. 2015, 21, 1224-1234.

50. Karoyo, A.H.; Sidhu, P.S.; Wilson, L.D.; Hazendonk, P.; Borisov, A. Counterion Anchoring Effect on the Structure of the Solid-State Inclusion Complexes of $\beta$-Cyclodextrin and Sodium Perfluorooctanoate. J. Phys. Chem. C 2015, 119, 22225-22243. [CrossRef]

51. Kong, D.; Wilson, L.D. Synthesis and Characterization of Cellulose-Goethite Composites and Their Adsorption Properties with Roxarsone. Carbohydr. Polym. 2017, 169, 282-294. [CrossRef] [PubMed] 
52. Gbenebor, O.P.; Akpan, E.I.; Adeosun, S.O. Thermal, Structural and Acetylation Behavior of Snail and Periwinkle Shells Chitin. Prog. Biomater. 2017, 6, 97-111. [CrossRef] [PubMed]

53. Moussout, H.; Ahlafi, H.; Aazza, M.; Bourakhouadar, M. Kinetics and Mechanism of the Thermal Degradation of Biopolymers Chitin and Chitosan Using Thermogravimetric Analysis. Polym. Degrad. Stab. 2016, 130, 1-9. [CrossRef]

54. Mohamed, M.H.; Udoetok, I.A.; Wilson, L.D.; Headley, J.V. Fractionation of Carboxylate Anions from Aqueous Solution Using Chitosan Cross-Linked Sorbent Materials. RSC Adv. 2015, 5, 82065-82077. [CrossRef]

55. Dehabadi, L.; Karoyo, A.H.; Wilson, L.D. Spectroscopic and Thermodynamic Study of Biopolymer Adsorption Phenomena in Heterogeneous Solid-Liquid Systems. ACS Omega 2018, 3, 15370-15379. [CrossRef]

56. Chiou, M.S.; Li, H.Y. Equilibrium and Kinetic Modeling of Adsorption of Reactive Dye on Cross-Linked Chitosan Beads. J. Hazard. Mater. 2002, 93, 233-248. [CrossRef]

57. An, B.; Choi, J.-W. An Experimental Application of Four Types of Chitosan Bead for Removal of Cationic and Anionic Pollutants. Water Air Soil Pollut. 2019, 230, 314. [CrossRef]

58. Mahaninia, M.H.; Wilson, L.D. Phosphate Uptake Studies of Cross-Linked Chitosan Bead Materials. J. Colloid Interface Sci. 2017, 485, 201-212. [CrossRef] [PubMed]

59. Peng, Y.; Fu, S.; Liu, H.; Lucia, L.A. Accurately Determining Esterase Activity via the Isosbestic Point of P-Nitrophenol. BioResources 2016, 11. [CrossRef]

60. Dragan, E.S.; Apopei Loghin, D.F.; Cocarta, A.I. Efficient Sorption of $\mathrm{Cu}^{2+}$ by Composite Chelating Sorbents Based on Potato Starch-Graft-Polyamidoxime Embedded in Chitosan Beads. ACS Appl. Mater. Interfaces 2014, 6, 16577-16592. [CrossRef]

61. Method of Sampling and Test (Physical and Chemical) for Water and Wastewater, Part 24: Sulphates (First Revision). Available online: http://www.iitk.ac.in/ce/test/IS-codes/is.3025.24.1986.pdf (accessed on 25 September 2020).

62. Poon, L.; Wilson, L.D.; Headley, J.V. Chitosan-Glutaraldehyde Copolymers and Their Sorption Properties. Carbohydr. Polym. 2014, 109, 92-101. [CrossRef]

63. Wilson, L.D.; Xue, C. Macromolecular Sorbent Materials for Urea Capture. J. Appl. Polym. Sci. 2013, 128, 667-675. [CrossRef]

64. Moret, A.; Rubio, J. Sulphate and Molybdate Ions Uptake by Chitin-Based Shrimp Shells. Miner. Eng. 2003, 16, 715-722. [CrossRef]

65. Xue, J.; Guo, Y.; Bi, Q.; Mao, W.; Li, J. Study in the Adsorption of Sulfate Ions onto Cross-Linked Chitosan. Mod. Phys. Lett. B 2013, 27, 1341031. [CrossRef]

66. GESTIS Substance Database. Available online: http://gestis-en.itrust.de/ (accessed on 24 August 2020).

67. Rashid, S.; Shen, C.; Yang, J.; Liu, J.; Li, J. Preparation and Properties of Chitosan-Metal Complex: Some Factors Influencing the Adsorption Capacity for Dyes in Aqueous Solution. J. Environ. Sci. 2018, 66, 301-309. [CrossRef]

68. Chen, W.; Liu, H. Adsorption of Sulfate in Aqueous Solutions by Organo-Nano-Clay: Adsorption Equilibrium and Kinetic Studies. J. Cent. South Univ. 2014, 21, 1974-1981. [CrossRef]

69. Hong, S.; Cannon, F.S.; Hou, P.; Byrne, T.; Nieto-Delgado, C. Adsorptive Removal of Sulfate from Acid Mine Drainage by Polypyrrole Modified Activated Carbons: Effects of Polypyrrole Deposition Protocols and Activated Carbon Source. Chemosphere 2017, 184, 429-437. [CrossRef] [PubMed]

70. Cao, W.; Dang, Z.; Zhou, X.Q.; Yi, X.Y.; Wu, P.X.; Zhu, N.W.; Lu, G.N. Removal of Sulphate from Aqueous Solution Using Modified Rice Straw: Preparation, Characterization and Adsorption Performance. Carbohydr. Polym. 2011, 85, 571-577. [CrossRef]

71. Sang, P.L.; Wang, Y.Y.; Zhang, L.Y.; Chai, L.Y.; Wang, H.Y. Effective Adsorption of Sulfate Ions with Poly(m-Phenylenediamine) in Aqueous Solution and Its Adsorption Mechanism. Trans. Nonferrous Met. Soc. China 2013, 23, 243-252. [CrossRef]

72. Weißpflog, J.; Boldt, R.; Kohn, B.; Scheler, U.; Jehnichen, D.; Tyrpekl, V.; Schwarz, S. Investigation of Mechanisms for Simultaneous Adsorption of Iron and Sulfate Ions onto Chitosan with Formation of Orthorhombic Structures. Colloids Surf. A Physicochem. Eng. Asp. 2020, 592, 124575. [CrossRef]

73. Tucker, B.B.; Kurtz, L.T. Calcium and Magnesium Determinations by EDTA Titrations. Soil Sci. Soc. Am. J. 1961, 25, 27-29. [CrossRef]

74. Solgi, M.; Tabil, L.G.; Wilson, L.D. Modified Biopolymer Adsorbents for Column Treatment of Sulfate Species in Saline Aquifers. Materials 2020, 13, 2408. [CrossRef] 
75. Yang, Y.; Chun, Y.; Sheng, G.; Huang, M. pH-Dependence of Pesticide Adsorption by Wheat-Residue-Derived Black Carbon. Langmuir 2004, 20, 6736-6741. [CrossRef]

76. Szymańska, E.; Winnicka, K. Stability of Chitosan-A Challenge for Pharmaceutical and Biomedical Applications. Mar. Drugs 2015, 13, 1819-1846. [CrossRef]

(C) 2020 by the authors. Licensee MDPI, Basel, Switzerland. This article is an open access article distributed under the terms and conditions of the Creative Commons Attribution (CC BY) license (http://creativecommons.org/licenses/by/4.0/). 